\title{
Measuring Financial Inclusion in Developing Economies: A Multidimensional Index
}

\author{
Nur Amirah Borhan ${ }^{1 *}$, Ruhaini Muda ${ }^{1,2}$ and Saadiah Mohamad ${ }^{1}$ \\ ${ }^{1}$ Faculty of Business and Management, \\ Universiti Teknologi MARA, Malaysia \\ ${ }^{2}$ Accounting Research Institute (HICoE), \\ Universiti Teknologi MARA, Malaysia
}

\begin{abstract}
Financial inclusion is a major policy concern especially in developing economies. However, an established measure of financial inclusion is still absent. This paper aims to fill this gap by measuring and examining the level of financial inclusion in 66 developing economies. A Financial Inclusion Index (FII) was constructed, incorporating five indicators (ATM, Bank, Other Financial Institutions, Deposits and Loans) for 2013 until 2019. Twostaged Factor Analysis was employed for weights assignment. The results showed that the average level of financial inclusion in developing economies was low but with significant variation among group of countries. A lower level of financial inclusion was observed among the African countries as well as the low-income and lower-middle income countries. The paper also analysed the relationship between financial inclusion and economic development. The findings showed that more developed economies had higher income and thus, higher financial inclusion. While the index is valid and reliable to be used for comparison among developing economies, the study was unable to include indicators of mobile and internet banking due to data constraints. Despite this caveat, the findings of this study will be useful for policymakers in shaping financial inclusion policies.
\end{abstract}

Keywords: financial inclusion, financial inclusion index, economic development, factor analysis

\section{ARTICLE INFO}

Article History:

Received: 24 July 2021

Accepted: 8 November 2021

Published: 1 December 2021

* Corresponding author: Nur Amirah Borhan. Email: nuramirahborhan@yahoo.com 


\section{INTRODUCTION}

While there are various definitions of financial inclusion, this paper defined it in simple terms as an individual's access and usage of basic financial services. Financial inclusion has become a global agenda and policy priority in many countries (Sarma \& Pais, 2011). While it is not explicitly listed as one of the United Nation's Sustainable Development Goals (SDGs), it is recognised as the key enabler of other development goals (UN Capital Development Fund, 2019). Thus, various financial inclusion policies and global initiatives have been put in place for the past two decades such as the World Bank's Universal Financial Access 2020 and Maya Declaration of Financial Inclusion (Wang \& Guan, 2017).

Generally, there have been significant progress in recent years to advance financial inclusion as evidenced by the improvement in several financial inclusion indicators. The latest statistics from World Bank i.e., the 2017 Global Findex Database reported that $69 \%$ of adults now own an account at formal financial institutions, an increase from $51 \%$ in 2011 . As a result of improved access, the usage of financial services has improved as well. For example, the share of adults reported having formally saved rose from $23 \%$ in 2011 to $27 \%$ in 2017 . Furthermore, $54 \%$ of the global adults are now able to come up with emergency funds (Demirguc-Kunt et al., 2018).

Nevertheless, financial inclusion still remains a major challenge in many countries although remarkable progress has been made globally in recent years (World Bank Group, 2018). 1.7 billion of adults worldwide are still without a formal bank account. In fact, nearly half of the global unbanked population came from just seven developing economies i.e. Bangladesh, China, India, Indonesia, Mexico, Nigeria and Pakistan (Demirguc-Kunt et al., 2018). Furthermore, the 2019 Financial Access Survey revealed that the African countries had the lowest number of deposit and loan account with commercial banks among the developing economies (International Monetary Fund, 2020).

Past studies have undoubtedly established the importance of financial inclusion, yet the research on financial inclusion is still insufficient in terms of measuring and assessing the level of financial inclusion across economies. Furthermore, establishing a comprehensive measure of financial 
inclusion is the first step to further examine other related issues pertaining to financial inclusion such as its factors and impacts. For instance, Beck, Demirguc-Kunt and Martinez Peria (2007) made the very first attempt to measure access to and usage of banking services across 99 countries. Sarma (2008) then filled the gap by being the first to propose a multidimensional financial inclusion index.

Against this backdrop, this study aimed to measure and examine the level of financial inclusion across 66 developing countries, and further analyse the relationship between financial inclusion and economic development. A multidimensional financial inclusion index (FII) was constructed, covering the period of 2013-2019. This new index included the indicator measuring access to other financial institutions which comprised microfinance institutions, credit cooperation and credit cooperatives in addition to the commonly used banking indicators. It would be interesting to examine how the addition of this new indicator could make a difference in the values of FII and the ranking of countries.

In addition, weights were assigned using factor analysis instead of assigning equal weight like done in most past studies. The study also focused on the developing economies which housed nearly half of the global unbanked population. Furthermore, the sample was further divided into geographical regions and income categories to examine the differences in financial inclusion between different groups of countries. The findings of this study may be useful for policymakers to measure the impact and success of financial inclusion policies and programs that have been put in place.

\section{LITERATURE REVIEW}

\section{The Concept of Financial Inclusion}

Financial intermediaries such as banks, microfinance, and licensed financial institutions pool funds from depositors and give them to borrowers who request financing (Bongomin et al., 2015). The financial intermediation theory explains the raisons d'etre of these financial intermediaries and their role towards financial inclusion and economic development (Swamy $\&$ Tulasimala, 2011). The financial intermediation process ensures that 
resources are efficiently channeled from the surplus units to the deficit units, thus reducing the cost of capital and improving financial inclusion. Access to finance can also stop the growth of informal financial services that are usually exploitative (Sarma \& Pais, 2011).

A growing body of literature has highlighted the importance of measuring financial inclusion and tracking its progress over time (Hannig \& Jansen, 2010; Porteous, 2009). However, the definition of financial inclusion has not yet been established. Scholars and policy makers have come up with numerous definitions of the concept. For example, the Scottish Government defined financial inclusion as an individual's access to appropriate financial products and services (Scottish Executive, 2005). On the other hand, Demirguc-Kunt, Beck, and Patrick (2007) viewed financial inclusion as a "broad access to financial services" and emphasized the need to remove barriers in the use of financial services. Sarma (2008) then described financial inclusion as a process that ensures the ease of access, availability, and usage of the formal financial systems for all members of an economy.

\section{Measuring Financial Inclusion}

Literature on financial inclusion still lacks a comprehensive measure that can be used to compare the level of financial inclusion across countries. Existing studies highlight the constraints in measuring financial inclusion such as the absence of a universal definition and lack of consistent data (Cámara \& Tuesta, 2017; Sarma, 2008). Due to the multidimensional nature of financial inclusion, a more comprehensive measure should be adopted such as by using the financial inclusion index which contains aggregate information of different dimensions of financial inclusion. The first pioneering research on the financial inclusion index is that of Sarma (2008). Sarma (2008) included three dimensions i.e., Penetration, Availability and Usage. The proposed index followed and improved the indexing approach done by the United Nation Development Program (UNDP) in constructing the Human Development Index (HDI).

Many other researchers later came up with a financial inclusion index which improved Sarma's methodology in terms of increasing the number of indicators used and using the latest data, making it more robust and indicative (Arora, 2010; Goel \& Sharma, 2017; Gupte, Venkataramani, \& 
Gupta, 2012; Mukherjee \& Malik, 2015; Piñeyro \& Manuel, 2013; Sethy, 2016). The most common dimensions used by most studies were the access and usage dimensions (Chakravarty \& Pal, 2013; Goel \& Sharma, 2017; Sarma, 2008, 2016; Yorulmaz, 2016). Several studies have also included other dimensions such as ease and cost dimensions (Arora, 2014; Gupte et al., 2012) and the barrier dimension (Cámara \& Tuesta, 2014). While using as many dimensions and indicators as possible will make the index more robust, researchers have to consider the availability of data.

The methodology used for weight assignment also varies between studies. Most researchers follow Sarma (2008) which assigns equal weight to all dimensions (Goel \& Sharma, 2017; Gupte et al., 2012; Kainth, 2013; Sarma, 2008; Sethy, 2016; Yorulmaz, 2016). Arora (2010) then assigns different weights to the dimensions based on the availability of data. On the other hand, Piñeyro and Manuel (2013) was the first to use the statistical method, particularly the Principal Component Analysis method, to assign weight to each dimension. Following that, Cámara and Tuesta (2014) and Mukherjee and Malik (2015) used the PCA method as well while Amidžić et al. (2014) employed the Factor Analysis method.

While there are many factors that may be associated with financial inclusion, the effect of economic development (i.e., GDP per capita) on financial inclusion has been generally established. Most past studies have found that GDP per capita had a significant positive influence on financial inclusion (Allen et al., 2014; Beck, Demirguc-Kunt, \& Peria, 2008; Evans \& Adeoye, 2016; Ghosh, 2012; Kendall, Ponce, \& Mylenko, 2010; Wang $\&$ Guan, 2017). This showed that economic development is one of the main determinants of financial inclusion and this variable is often included in most studies. Furthermore, the reliability of a newly constructed index is often proved by regressing the index over GDP per capita such as done by Abu Seman (2016). 


\section{METHODOLOGY}

\section{Sample and Data}

The sample of this study was developing countries. The study chose to assess the level of financial inclusion in this set of countries because financial inclusion is a pressing issue in the developing world, especially African countries. Furthermore, nearly half of the global unbanked adults came from the developing world. The study period chosen was from 2013 to 2019 (7 years). Including the earlier period i.e., pre-2013 would cause more countries to be eliminated from the sample, while data for 2020 was unavailable for many countries due to lack of reporting amidst the global COVID-19 pandemic.

The secondary data were all collected from the International Monetary Fund's Financial Access Survey (FAS). FAS is a widely recognized as the best available and commonly used database reporting the supply-side data on financial inclusion. Initially there were 99 developing countries but 33 countries were eliminated due to extreme missing data. The eliminated countries were either not reporting their data to the IMF (e.g., Bahrain, Somalia, Taiwan), or had missing values for almost all indicators (e.g., Gabon, Syria, Vanuatu). The study ended up with a sample of 66 developing countries, but there were still several countries with slight missing values for some indicators or time period. Therefore, the linear regression imputation was used to substitute these missing values.

\section{Indicators and Dimensions}

Data availability is the main concern in measuring financial inclusion. While there are other relevant indicators such as mobile money, internet banking and payment, data for measuring these indicators are unavailable for most developing countries, thus had to be excluded in our study. Therefore, we incorporated two main dimensions which comprised five indicators as explained in Table 1.

An inclusive financial system should be easily accessible to all users. Access is usually measured using geographic or demographic penetration. This study used geographic penetration of the banking system 
which comprised the number of ATMs and bank branches per 1,000 km2. Furthermore, we also included the number of other financial intermediaries per 1,000 km2 which comprised of microfinance institutions, credit unions and credit cooperatives. Geographic penetration was preferred because location of physical access points has often been cited as one of the main causes of financial exclusion (Beck et al., 2008; Kempson, 2004).

For the usage dimension, this study considered the two main services of the financial system i.e., deposit and loan. While Amidžić et al. (2014) used deposit and loan account per 1,000 adults to represent usage, total outstanding deposits and loans as percentage of GDP as proposed by Sarma (2008) was found to be more reliable. This is because merely having an account is not a good representation of usage if they are not effectively utilized (Sarma, 2008, 2016). Kempson (2004) also observed that while the proportion of people with a bank account was high in some countries, very few utilized the service.

Table 1: Dimensions and Indicators Used in Constructing the Financial Inclusion Index (FII)

\begin{tabular}{lll}
\hline Dimensions & Indicators & \multicolumn{1}{c}{ Measurement } \\
Access & ATM & $\begin{array}{l}\text { No. of Automated Teller Machines (ATMs) per } \\
1,000 \mathrm{~km}^{2}\end{array}$ \\
& BANK & $\begin{array}{l}\text { No. of commercial bank branches per } 1,000 \mathrm{~km}^{2} \\
\text { No. of other financial intermediaries per } 1,000 \mathrm{~km}^{2}\end{array}$ \\
& OTHERS & Total outstanding deposits (percentage of GDP) \\
\hline Usage & DEPO & Total outstanding loans (percentage of GDP) \\
& LOAN & Total
\end{tabular}

\section{Multidimensional Financial Inclusion Index (FII) Construction}

This study used a quantitative research method, particularly Factor Analysis, to construct the financial inclusion index (FII). Applying Factor Analysis to various financial inclusion indicators allowed us to; 1) analyse the relationship between items and how they confirm to the intended construct, 2) support the relationship between items as suggested by the theoretical framework (Tavakol \& Wetzel, 2020). By adopting and revising the methods done by Sarma (2008), Amidžić et al. (2014) and Wang and Guan (2017), as well as referring to the OECD's handbook on constructing composite indicators (OECD, 2008), a multidimensional approach was 
implemented following a five-step sequence as follows; 1) treatment of outliers, 2) ensuring adequate correlation, 3) normalization, 4) weights assignment, and 5) aggregation.

The study analysed the descriptive statistics of the indicators as shown in Table 2. As evident, the standard deviation of all indicators was high, highly skewed and had a high kurtosis, indicating the presence of outliers and extreme values. Factor Analysis is very sensitive to outliers, thus the data was winsorised at 97\% as suggested by Wang and Guan (2017) in order to keep all data for further analysis rather than removing the observations.

Table 2: Dimensions and Indicators Used in Constructing the Financial Inclusion Index (FII)

\begin{tabular}{lccccc} 
& ATM & BANK & OTHERS & DEPO & LOAN \\
\hline Mean & 85.036 & 15.858 & 13.706 & 57.266 & 48.334 \\
Minimum & 0.050 & 0.098 & 0.002 & 10.325 & 2.809 \\
Maximum & 4506.347 & 437.236 & 254.867 & 253.900 & 223.629 \\
Std. Deviation & 498.775 & 51.699 & 37.280 & 46.705 & 40.157 \\
Skewness & 7.923 & 6.827 & 4.425 & 2.051 & 1.366 \\
Kurtosis & 64.380 & 52.028 & 23.668 & 7.585 & 4.747 \\
Observations (N) & 462 & 462 & 462 & 462 & 462 \\
\hline
\end{tabular}

Since Factor Analysis is based on correlation, it must be ensured that at least two indicators are correlated at 0.30 or greater because correlation value of less than 0.3 indicates weak relationship between indicators (Mukaka, 2012; Ratner, 2009). The correlations between the five indicators were all found to be more than 0.30 , with the exception of the correlations between OTHERS and ATM, DEPO and LOAN. This showed that the indicators explained the same construct i.e., financial inclusion.

The Kaiser-Meyer-Olkin (KMO) Measure of Sampling Adequacy and the Bartlett Test of Sphericity were done before conducting Factor Analysis to further verify adequate correlations between indicators. The KMO statistic was 0.575 , which was more than the minimum required threshold $(0.50)$, while the Bartlett Test statistic was 75.975 statistically significant at the 1\% level of confidence. These supported that the indicators were correlated and suitable for structure detection using Factor Analysis. 
The indicators were then normalized using the min-max normalization method to render them comparable. Formula (1) as employed by Sarma (2008) was used. Normalization ensures the value of falls between 0 and 1. For each indicator, the study computed as follows:

$$
d_{i}=\frac{A_{i}-m_{i}}{M_{i}-m_{i}}
$$

Where,

$d_{i}$ : Normalized value of indicator $i$,

$A_{i}$ : Actual value of indicator $i$,

$m_{i}$ : Observed minimum value of indicator $i$

$M_{i}$ : Observed maximum value of indicator $i$.

While Sarma (2008) uses equal weights and Wang and Guan (2017) used coefficient of variation, this study assigned weights by using a twostaged Factor Analysis following Amidžić et al. (2014). In the first stage, the study estimated the weights of the indicators representing the two dimensions and calculated the dimensional indices. In the second stage, the study then estimated the weights of the two dimensions and calculated the composite financial inclusion index (FII). This strategy is ideal as it firstly estimates the dimensional indices instead of estimating the overall composite index directly, thus solving the issue of weight bias of highly correlated indicators (OECD, 2008).

Factor Analysis was used to identify and extract the number of latent factors. Based on Kaiser's criterion, two factors had eigenvalues of more than 1 and cumulatively explained $84.60 \%$ of the total variance. This suggested that two factors should be retained. The indicator was then grouped under a factor that it loaded the most. ATM, BANK and OTHERS heavily loaded onto Factor 1 which represented the Access Dimension, while DEPO and LOAN loaded heavily onto Factor 2 which represented the Usage Dimension. The dimensions identified using Factor Analysis and the indicators included under them confirm with those mentioned in the literature. 
Furthermore, Factor Analysis addresses the criticisms of equal weighting and the lack of statistical rigor as done by Sarma (2008) by assigning weights which reflects the statistical importance of the indicators and dimensions. Table 3 shows the weights that were derived from matrix of rotated factor loadings. The usage dimension had a higher weight than the access dimension, showing that it was more important in explaining financial inclusion. This is because while access to financial services is a critical element of financial inclusion, access is meaningless without usage of the service (Salazar, Marra, Shnayerson, \& Menon, 2018).

Table 3: Weights of The Indicators and Dimensions

\begin{tabular}{lccc}
\multicolumn{1}{c}{$\begin{array}{c}\text { Indicator } \\
(\boldsymbol{i})\end{array}$} & $\begin{array}{c}\text { Indicator's Weight } \\
\left(\boldsymbol{w}_{\boldsymbol{i}}\right)\end{array}$ & $\begin{array}{c}\text { Dimension } \\
(\boldsymbol{d})\end{array}$ & $\begin{array}{c}\text { Dimension's Weight } \\
\left(\boldsymbol{w}_{\boldsymbol{d}}\right)\end{array}$ \\
\hline ATM & 0.221 & & \\
BANK & 0.528 & Access & 0.486 \\
OTHERS & 0.251 & & \\
\hline DEPO & 0.454 & Usage & 0.514 \\
LOAN & 0.546 & & \\
\hline
\end{tabular}

Following Wang and Guan (2017), the FII for the $\mathrm{i}^{\text {th }}$ country was measured by the weighted normalized inverse Euclidean distance of point $\mathrm{D}^{i}$ from the ideal point I, as shown in Formula (2) for the dimensional indices and in Formula (3) for the composite index. Country $i$ was represented by a point $\mathrm{D}_{i}=\left(d_{1}, d_{2}, \ldots, d_{n}\right)$ on the $\mathrm{n}$-dimensional Cartesian space. Point $\mathrm{O}=$ $(0,0, \ldots 0)$ represented the lowest achievement in all dimensions while point $I=(1,1, \ldots 1)$ represented the best-case scenario. The inverse Euclidean distance method was used so that a higher value of FII implied a higher level of financial inclusion.

$$
F I I_{D_{c}}^{t}=1-\frac{\sqrt{w_{i_{1}}^{2}\left(1-d_{i_{1}}\right)^{2}+w_{i_{2}}^{2}\left(1-d_{i_{2}}\right)^{2}+\cdots+w_{i_{n}}^{2}\left(1-d_{i_{n}}\right)^{2}}}{\sqrt{\left(w_{i_{1}}^{2}+w_{i_{2}}^{2}+\cdots+w_{i_{n}}^{2}\right)}}
$$

Where,

$F I I_{D_{c}}^{t}=$ Dimensional indices of country $c$ at time $t$ 
where $D_{1}=$ Access and $D_{2}=$ Usage

$w_{i}=$ Corresponding weight of indicator $i$

$d_{i}=$ Normalized value of indicator $i$

$F I I_{c}^{t}=1-\frac{\sqrt{w_{d_{1}}^{2}\left(1-F I I_{d_{1}}\right)^{2}+w_{d_{2}}^{2}\left(1-F I I_{d_{2}}\right)^{2}}}{\sqrt{\left(w_{d_{1}}^{2}++w_{d_{2}}^{2}\right)}}$

Where,

$F I I_{c}^{t}=$ FII of country $c$ at time $t$

$w d_{i}=$ Corresponding weight of dimension $i$,

where $d_{i}=$ Access and $d_{2}=$ Usage

$F I I_{D_{c}}^{t}=$ Dimensional indices $i$ of country $c$ at time $t$

While the geometric aggregator was used by Amidžić et al. (2014), Nathan, Mishra, and Reddy (2008) have shown that distance from the ideal approach is better in addressing the issue of perfect substitutability, and therefore making our index more reliable. Furthermore, in Amidžić et al. (2014) the sample was relatively small (31 countries), while our sample was bigger and covered the most recent year, thus making our index more robust and comprehensive. In addition, to assess the validity of the index, the newly constructed FII was compared with the best comparable development index that is the UNDP's HDI. Kendall's rank correlation coefficient (Kendall's Tau) was used to evaluate the degree of similarity between the ranking of countries based on the FII with the UNDP's HDI.

\section{Empirical Model}

It has been established that GDP per capita which represents the level of economic development is an important factor in influencing financial inclusion. Thus, to examine the relationship between these two variables and further prove the reliability of the index, the following model was estimated using the Panel Ordinary Least Squares (OLS) regression: 


$$
F I I_{i t}=\beta_{0}+\beta_{1} L N G D P_{i t}+\varepsilon_{i t}
$$

Where, $F I I_{i t}=$ Financial Inclusion Index

$L N G D P_{i t}=$ Natural logarithm of GDP per capita (current USD)

\section{RESULTS AND DISCUSSION}

\section{Validity of the Index}

A 7-year average FII values and the corresponding 7-year average HDI values for the countries were calculated along with their ranks. The estimated value of Kendall's Tau was 0.492 , statistically significant at the $1 \%$ level of significance. Since Kendall's Tau was more than 0.30 , it can be concluded that the FII and HDI moved in the same direction and were consistent with each other, showing that the FII constructed in this study was valid and can be used to compare the performance of countries in terms of financial inclusion.

\section{FIl for Developing Economies, 2013-2019}

Since the study managed to collect balanced panel data, the number of countries in the FII was similar throughout the 7-year period. Table 5 presents the computed FII values for 66 developing economies for the year 2013-2019. Depending on the value of the FII, countries were categorised into three levels as proposed by Sarma (2008):

1. $0 \leq \mathrm{FII}<0.3$ categorised as low financial inclusion

2. $0.3 \leq \mathrm{FII}<0.5$ categorised as medium financial inclusion

3. $0.5 \leq \mathrm{FII} \leq 1$ categorised as high financial inclusion

From Table 4, several observations were noted. The average FII value in the developing economies was 0.174 which falls under low financial inclusion category. 24 countries managed to score above the average FII level. While these 24 countries were predominantly Asian countries, there was heterogeneity in terms of income categories. For instance, Nepal is a low-income country whereas Jordan in an upper-middle income country. On the other hand, the remaining 42 countries in the sample were below 
the average FII level. These countries were mostly from the African region and generally were either low-income or lower-middle income countries, with some exception such as South Africa (upper-middle income) and Saudi Arabia (high income).

It is interesting to observe that Bangladesh ranked the highest among the low-income countries at the $4^{\text {th }}$ spot. Bangladesh particularly has a very high number of branches of other financial intermediaries. In particular, microfinance institutions (MFIs) have played a predominant role in India by extending its service beyond microcredit to include micro savings (Gustafson \& Khander, 2016). A recent study by Cámara and Tuesta (2017) ranked Bangladesh near the top as well since they also included indicators of both banking sectors and other financial institutions. However, some past studies such as Sarma (2008) and Arora (2010) ranked Bangladesh near the bottom because they included only banking sector indicators. This shows that excluding important indicators may undermine the real value of FII particularly for countries that highly rely on these institutions. Thus, by adding these indicators, our index is more robust as it captures additional information on financial inclusion that are often overlooked by others.

In addition, Nepal had a medium level of financial inclusion despite being a low-income country. While Nepal is far behind other South Asian countries like Bangladesh, India, and Sri Lanka, the financial inclusion in Nepal has been improving steadily over time, from 0.218 in 2013 to 0.419 in 2019 and averaging at 0.308 . The expansion of financial access remained impressive in recent years. Between 2017 to 2019, the Financial Access Survey reported that the number of branches of other financial intermediaries increased by almost double, reaching 4959 from 2668 (International Monetary Fund, 2020). According to Shrestha (2020), Nepal leverages on a wider network of other financial intermediaries to reach people at the bottom of the pyramid by providing financial services at lower costs. 
Table 4: Financial Inclusion Index for 66 Developing Economies, 2013-2019 $\begin{array}{llllllllll}\text { Country } & 2013 & 2014 & 2015 & 2016 & 2017 & 2018 & 2019 & \text { Avg. } & \text { Rank } \begin{array}{c}\text { Income } \\ \text { Level }\end{array}\end{array}$

\section{Panel A: Asian Countries}

\begin{tabular}{|c|c|c|c|c|c|c|c|c|c|c|}
\hline Singapore & 0.820 & 0.817 & 0.799 & 0.805 & 0.790 & 0.779 & 0.801 & 0.802 & 1 & $\mathrm{H}$ \\
\hline Lebanon & 0.656 & 0.669 & 0.674 & 0.682 & 0.688 & 0.674 & 0.643 & 0.669 & 2 & UM \\
\hline Bangladesh & 0.407 & 0.427 & 0.442 & 0.445 & 0.454 & 0.455 & 0.454 & 0.441 & 3 & LM \\
\hline China & 0.393 & 0.402 & 0.419 & 0.422 & 0.423 & 0.427 & 0.427 & 0.416 & 4 & UM \\
\hline India & 0.344 & 0.369 & 0.381 & 0.387 & 0.388 & 0.387 & 0.400 & 0.379 & 5 & LM \\
\hline Sri Lanka & 0.337 & 0.349 & 0.377 & 0.385 & 0.389 & 0.398 & 0.411 & 0.378 & 6 & UM \\
\hline Thailand & 0.371 & 0.380 & 0.384 & 0.381 & 0.376 & 0.376 & 0.373 & 0.377 & 7 & UM \\
\hline Qatar & 0.279 & 0.308 & 0.370 & 0.415 & 0.406 & 0.366 & 0.404 & 0.364 & 8 & $\mathrm{H}$ \\
\hline Vietnam & 0.316 & 0.329 & 0.349 & 0.368 & 0.369 & 0.379 & 0.386 & 0.357 & 9 & LM \\
\hline $\begin{array}{l}\text { United Arab } \\
\text { Emirates }\end{array}$ & 0.316 & 0.330 & 0.367 & 0.377 & 0.362 & 0.354 & 0.359 & 0.352 & 10 & $\mathrm{H}$ \\
\hline Kuwait & 0.260 & 0.288 & 0.363 & 0.380 & 0.367 & 0.350 & 0.362 & 0.339 & 11 & $\mathrm{H}$ \\
\hline Malaysia & 0.322 & 0.320 & 0.318 & 0.313 & 0.304 & 0.307 & 0.305 & 0.313 & 12 & UM \\
\hline Nepal & 0.218 & 0.230 & 0.265 & 0.305 & 0.341 & 0.379 & 0.419 & 0.308 & 14 & $\mathrm{~L}$ \\
\hline Jordan & 0.282 & 0.280 & 0.289 & 0.296 & 0.299 & 0.301 & 0.301 & 0.292 & 15 & UM \\
\hline Cambodia & 0.149 & 0.190 & 0.222 & 0.245 & 0.258 & 0.284 & 0.306 & 0.236 & 18 & LM \\
\hline Turkey & 0.221 & 0.228 & 0.235 & 0.244 & 0.243 & 0.236 & 0.233 & 0.234 & 19 & UM \\
\hline Philippines & 0.175 & 0.189 & 0.202 & 0.221 & 0.230 & 0.234 & 0.241 & 0.213 & 20 & LM \\
\hline Iran & 0.149 & 0.175 & 0.205 & 0.218 & 0.225 & 0.225 & 0.199 & 0.199 & 21 & UM \\
\hline Brunei & 0.167 & 0.172 & 0.206 & 0.213 & 0.195 & 0.185 & 0.189 & 0.190 & 22 & $\mathrm{H}$ \\
\hline Fiji & 0.164 & 0.171 & 0.182 & 0.189 & 0.190 & 0.191 & 0.195 & 0.183 & 23 & UM \\
\hline Indonesia & 0.174 & 0.180 & 0.183 & 0.185 & 0.183 & 0.183 & 0.181 & 0.181 & 24 & LM \\
\hline Samoa & 0.153 & 0.165 & 0.153 & 0.176 & 0.177 & 0.194 & 0.192 & 0.173 & 25 & UM \\
\hline Oman & 0.110 & 0.125 & 0.164 & 0.181 & 0.179 & 0.172 & 0.191 & 0.160 & 28 & $\mathrm{H}$ \\
\hline Saudi Arabia & 0.128 & 0.144 & 0.178 & 0.185 & 0.169 & 0.153 & 0.154 & 0.159 & 30 & $\mathrm{H}$ \\
\hline Mongolia & 0.136 & 0.135 & 0.124 & 0.137 & 0.136 & 0.150 & 0.145 & 0.138 & 34 & LM \\
\hline Lao PDR & 0.095 & 0.102 & 0.112 & 0.124 & 0.128 & 0.125 & 0.133 & 0.117 & 36 & LM \\
\hline Pakistan & 0.099 & 0.102 & 0.106 & 0.115 & 0.119 & 0.135 & 0.139 & 0.116 & 37 & LM \\
\hline Timor-Leste & 0.049 & 0.054 & 0.060 & 0.069 & 0.085 & 0.088 & 0.068 & 0.068 & 45 & LM \\
\hline Myanmar & 0.017 & 0.030 & 0.039 & 0.051 & 0.062 & 0.070 & 0.091 & 0.052 & 53 & LM \\
\hline Solomon Islands & 0.033 & 0.037 & 0.043 & 0.047 & 0.047 & 0.048 & 0.053 & 0.044 & 55 & LM \\
\hline Iraq & 0.019 & 0.022 & 0.032 & 0.030 & 0.027 & 0.020 & 0.018 & 0.024 & 61 & UM \\
\hline Yemen & 0.017 & 0.015 & 0.013 & 0.016 & 0.012 & 0.009 & 0.007 & 0.013 & 64 & $\mathrm{~L}$ \\
\hline Afghanistan & 0.006 & 0.007 & 0.008 & 0.010 & 0.010 & 0.009 & 0.006 & 0.008 & 66 & $\mathrm{~L}$ \\
\hline \multicolumn{11}{|c|}{ Panel B: African Countries } \\
\hline Mauritania & 0.307 & 0.313 & 0.313 & 0.313 & 0.313 & 0.314 & 0.314 & 0.312 & 13 & LM \\
\hline Morocco & 0.283 & 0.287 & 0.284 & 0.289 & 0.289 & 0.292 & 0.292 & 0.288 & 16 & LM \\
\hline Tunisia & 0.222 & 0.227 & 0.232 & 0.240 & 0.252 & 0.254 & 0.251 & 0.240 & 17 & LM \\
\hline
\end{tabular}




\begin{tabular}{|c|c|c|c|c|c|c|c|c|c|c|}
\hline Country & 2013 & 2014 & 2015 & 2016 & 2017 & 2018 & 2019 & Avg. & Rank & $\begin{array}{c}\text { Income } \\
\text { Level }\end{array}$ \\
\hline South Africa & 0.169 & 0.171 & 0.175 & 0.172 & 0.170 & 0.170 & 0.172 & 0.171 & 26 & UM \\
\hline $\begin{array}{l}\text { Sao Tome and } \\
\text { Principe }\end{array}$ & 0.191 & 0.177 & 0.182 & 0.175 & 0.160 & 0.149 & 0.147 & 0.169 & 27 & LM \\
\hline Togo & 0.141 & 0.152 & 0.155 & 0.169 & 0.157 & 0.169 & 0.174 & 0.160 & 29 & $\mathrm{~L}$ \\
\hline Sudan & 0.153 & 0.154 & 0.164 & 0.168 & 0.158 & 0.159 & 0.116 & 0.153 & 31 & LM \\
\hline South Sudan & 0.125 & 0.201 & 0.154 & 0.147 & 0.117 & 0.127 & 0.188 & 0.151 & 32 & $\mathrm{~L}$ \\
\hline Egypt & 0.107 & 0.120 & 0.137 & 0.190 & 0.175 & 0.166 & 0.155 & 0.150 & 33 & LM \\
\hline Rwanda & 0.104 & 0.111 & 0.124 & 0.127 & 0.126 & 0.129 & 0.120 & 0.120 & 35 & $\mathrm{~L}$ \\
\hline Kenya & 0.095 & 0.114 & 0.114 & 0.107 & 0.100 & 0.108 & 0.092 & 0.104 & 38 & LM \\
\hline Senegal & 0.079 & 0.086 & 0.092 & 0.097 & 0.105 & 0.110 & 0.113 & 0.097 & 39 & LM \\
\hline Djibouti & 0.081 & 0.089 & 0.088 & 0.085 & 0.089 & 0.092 & 0.094 & 0.088 & 40 & LM \\
\hline Burkina Faso & 0.065 & 0.076 & 0.084 & 0.085 & 0.096 & 0.096 & 0.103 & 0.086 & 41 & $\mathrm{~L}$ \\
\hline Mozambique & 0.071 & 0.092 & 0.089 & 0.085 & 0.075 & 0.072 & 0.073 & 0.079 & 42 & $L$ \\
\hline Comoros & 0.061 & 0.066 & 0.074 & 0.084 & 0.082 & 0.088 & 0.097 & 0.079 & 43 & $\mathrm{~L}$ \\
\hline Zimbabwe & 0.046 & 0.050 & 0.043 & 0.053 & 0.059 & 0.060 & 0.238 & 0.078 & 44 & LM \\
\hline Gambia & 0.072 & 0.073 & 0.063 & 0.059 & 0.060 & 0.069 & 0.075 & 0.067 & 46 & $\mathrm{~L}$ \\
\hline Benin & 0.058 & 0.064 & 0.066 & 0.070 & 0.067 & 0.067 & 0.074 & 0.067 & 47 & $\mathrm{~L}$ \\
\hline Ghana & 0.050 & 0.058 & 0.068 & 0.070 & 0.069 & 0.063 & 0.067 & 0.063 & 48 & LM \\
\hline Burundi & 0.066 & 0.069 & 0.059 & 0.063 & 0.059 & 0.063 & 0.064 & 0.063 & 49 & $\mathrm{~L}$ \\
\hline Angola & 0.062 & 0.065 & 0.080 & 0.070 & 0.055 & 0.051 & 0.049 & 0.062 & 50 & LM \\
\hline Mali & 0.048 & 0.054 & 0.062 & 0.067 & 0.066 & 0.067 & 0.068 & 0.062 & 51 & $\mathrm{~L}$ \\
\hline Cote d'Ivoire & 0.052 & 0.057 & 0.045 & 0.050 & 0.056 & 0.061 & 0.064 & 0.055 & 52 & LM \\
\hline Nigeria & 0.050 & 0.054 & 0.049 & 0.053 & 0.045 & 0.041 & 0.039 & 0.047 & 54 & LM \\
\hline Cameroon & 0.031 & 0.031 & 0.038 & 0.039 & 0.040 & 0.036 & 0.039 & 0.036 & 56 & LM \\
\hline Tanzania & 0.029 & 0.031 & 0.035 & 0.035 & 0.036 & 0.038 & 0.038 & 0.034 & 57 & $\mathrm{~L}$ \\
\hline Uganda & 0.028 & 0.029 & 0.031 & 0.031 & 0.029 & 0.029 & 0.031 & 0.030 & 58 & $L$ \\
\hline Guinea-Bissau & 0.024 & 0.026 & 0.032 & 0.027 & 0.021 & 0.031 & 0.036 & 0.028 & 59 & $\mathrm{~L}$ \\
\hline Zambia & 0.025 & 0.028 & 0.037 & 0.024 & 0.024 & 0.026 & 0.028 & 0.027 & 60 & LM \\
\hline Madagascar & 0.010 & 0.012 & 0.016 & 0.017 & 0.021 & 0.021 & 0.021 & 0.017 & 62 & $\mathrm{~L}$ \\
\hline Niger & 0.012 & 0.013 & 0.015 & 0.018 & 0.016 & 0.014 & 0.017 & 0.015 & 63 & $\mathrm{~L}$ \\
\hline Guinea & 0.003 & 0.011 & 0.013 & 0.012 & 0.009 & 0.014 & 0.019 & 0.011 & 65 & $\mathrm{~L}$ \\
\hline Overall Average & & & & & & & & 0.174 & & \\
\hline
\end{tabular}

Note: $\mathrm{H}$ indicates High-income, UM indicates Upper-middle income, LM indicates Lower-middle income, L indicates Low-income

Generally, there has been an improvement in the level of financial inclusion in developing economies over the years. This is evident as there is a gradual increase in the number of countries with a medium level of inclusion which symmetrically resulted from the gradual decrease of countries with low level of inclusion. As illustrated in Figure 1, the number of countries 
in low FII category decreased from 55 countries in 2013 to 50 countries in 2019. This finding is consistent with recent studies done by Sarma (2016) and Park and Mercado (2018) as they also found that proportion of countries in low FII category were decreasing throughout the years. Thus, even though most of the developing countries fall under low FII category, the FII values are improving throughout the years, suggesting that these countries are making significant progress in financial inclusion albeit in a small way for some countries.

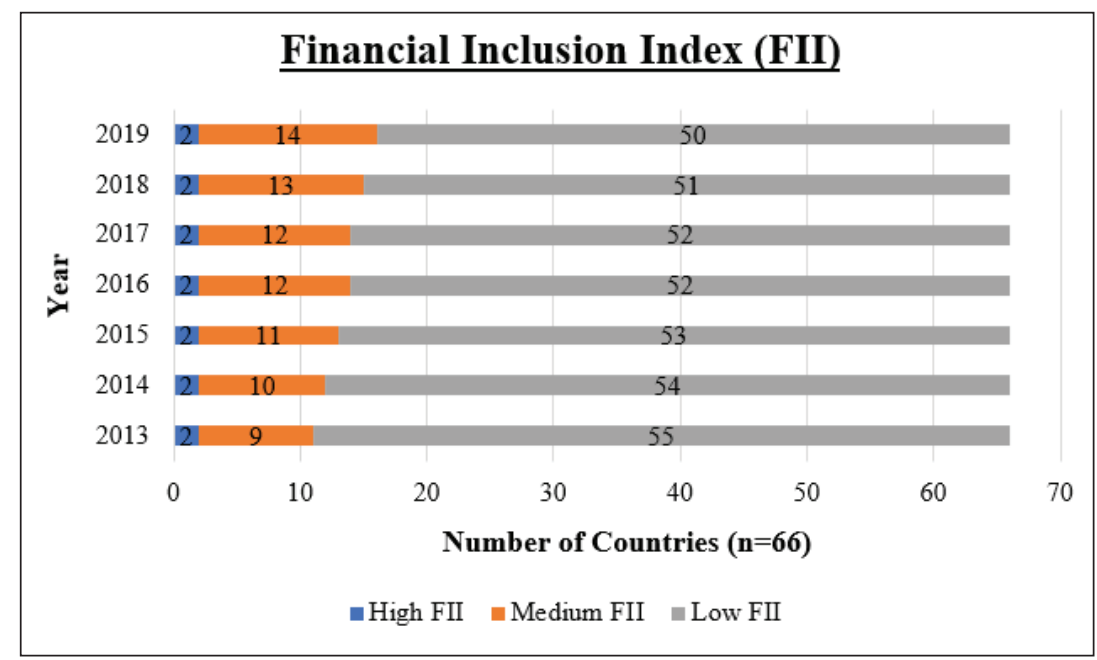

Figure 1: The Number of Countries in High, Medium and Low Level of Inclusion

There was also a significant variation in the level of financial inclusion across developing economies. A few economies had very high FII, while others had a medium or terribly low FII. Singapore and Lebanon were at the top of the ranking with an average FII values of 0.802 and 0.669 respectively. These two countries consistently had high FII values during the 7 year period. 12 countries belonged in the medium FII category. They were Bangladesh, China, India, Sri Lanka, Thailand, Qatar, Vietnam, United Arab Emirates, Kuwait, Malaysia, Mauritania, and Nepal. On the other hand of the spectrum, the remaining 52 countries were in the low FII category. Some countries had an abysmally low level of financial inclusion $(\mathrm{FII}<0.05)$ and these were Nigeria, Solomon Islands, Cameroon, Tanzania, Uganda, Guinea-Bissau, Zambia, Iraq, Madagascar, Niger, Yemen, Guinea, and Afghanistan. 


\section{FIl by Geographical Regions}

Table 5: Descriptive Statistics of FII Values of Developing Economies Grouped by Geographical Regions, 2013-2019

\begin{tabular}{lccccccc}
\hline & $\mathbf{2 0 1 3}$ & $\mathbf{2 0 1 4}$ & $\mathbf{2 0 1 5}$ & $\mathbf{2 0 1 6}$ & $\mathbf{2 0 1 7}$ & $\mathbf{2 0 1 8}$ & $\mathbf{2 0 1 9}$ \\
\hline Panel A: Asian countries & & & & & & & \\
\hline Mean & 0.224 & 0.235 & 0.250 & 0.261 & 0.262 & 0.262 & 0.266 \\
Total no. of countries & 33 & 33 & 33 & 33 & 33 & 33 & 33 \\
No. of high FII countries & 2 & 2 & 2 & 2 & 2 & 2 & 2 \\
No. of medium Fll countries & 8 & 9 & 10 & 11 & 11 & 12 & 13 \\
No. of low FII countries & 23 & 22 & 21 & 20 & 20 & 19 & 18 \\
\hline Panel B: African countries & & & & & & & \\
\hline Mean & 0.088 & 0.096 & 0.097 & 0.100 & 0.097 & 0.098 & 0.105 \\
Total no. of countries & 33 & 33 & 33 & 33 & 33 & 33 & 33 \\
No. of high FIl countries & 0 & 0 & 0 & 0 & 0 & 0 & 0 \\
No. of medium Fll countries & 1 & 1 & 1 & 1 & 1 & 1 & 1 \\
No. of low FII countries & 32 & 32 & 32 & 32 & 32 & 32 & 32 \\
\hline
\end{tabular}

As evident, the average FII value of developing Asian countries were consistently improving over time, from 0.224 in 2013 to 0.266 in 2019. While more than half of the developing Asian countries were in the low FII category, the number of countries in this category decreased over the years. In 2013, 23 countries had low FII values but the number declined to 18 countries by 2019 . Accordingly, the number of countries in the medium FII category increased. There were also 2 developing Asian countries with high FII values throughout the 7-year period.

In contrast, the highest average FII recorded for the developing African countries was only 0.105 , which was still lower than the lowest average FII of the Asian countries. Furthermore, 32 out of 33 countries consistently fell under the low FII category throughout the 7-year period, while the remaining 1 country (i.e., Mauritania) was in the medium FII category. There was no country with a high level of financial inclusion in this group.

The findings showed that the developing Asian countries performed better in financial inclusion as opposed to their African counterparts. Furthermore, from Table 4, it is evident that the upper half of the ranking were dominated by Asian countries while the African countries were mostly 
in in the bottom of the ranking. Similar patterns could be observed in past studies such as Sarma (2008), Sarma and Pais (2011), Amidžić et al. (2014) and Cámara and Tuesta (2014) to name a few.

\section{FII by Income Categories}

Table 6: Descriptive Statistics of FII Values of Developing Economies Grouped by Income Categories, 2013-2019

\begin{tabular}{lccccccc}
\hline & 2013 & 2014 & $\mathbf{2 0 1 5}$ & $\mathbf{2 0 1 6}$ & $\mathbf{2 0 1 7}$ & $\mathbf{2 0 1 8}$ & $\mathbf{2 0 1 9}$ \\
\hline Panel A: Rich countries (high and upper-middle income group) & & & \\
\hline Mean & 0.280 & 0.290 & 0.310 & 0.319 & 0.315 & 0.309 & 0.312 \\
Total no. of countries & 19 & 19 & 19 & 19 & 19 & 19 & 19 \\
No. of high FIl countries & 2 & 2 & 2 & 2 & 2 & 2 & 2 \\
No. of medium FIl countries & 5 & 6 & 7 & 7 & 7 & 8 & 8 \\
No. of low FIl countries & 12 & 11 & 10 & 10 & 10 & 9 & 9 \\
\hline Panel B: Poor countries (lower-middle and low-income group) & & & \\
\hline Mean & 0.106 & 0.115 & 0.119 & 0.124 & 0.125 & 0.128 & 0.135 \\
Total no. of countries & 47 & 47 & 47 & 47 & 47 & 47 & 47 \\
No. of high Fll countries & 0 & 0 & 0 & 0 & 0 & 0 & 0 \\
No. of medium FIl countries & 4 & 4 & 4 & 5 & 5 & 5 & 6 \\
No. of low FIl countries & 43 & 43 & 43 & 42 & 42 & 42 & 41 \\
\hline
\end{tabular}

This study presented the categorisation of countries into two as in Panel A for rich countries comprising the high and upper-middle income group, while Panel B for poor countries comprising the lower-middle and low-income group. This categorisation of countries has been done previously by Sarma (2016) in Measuring Financial Inclusion for Asian Economies.

Table 6 shows that the relatively richer developing countries (highincome and upper middle-income) had average FII values ranging between a minimum of 0.280 and a maximum of 0.319 . While more than half of the rich countries had a low level of financial inclusion, there were improvements in their FII values as the number of countries that belonged in the low FII group decreased over the years. Likewise, the number of countries with medium FII values increased from 5 countries in 2013 to 8 countries in 2019, while the number of countries with a high FII were constant at 2 countries. 
The average FII values of the relatively poor economies (low income and lower-middle income) had shown gradual improvement over the years as well, from 0.106 in 2013 to 0.135 in 2019. As expected, a huge majority of the relatively poor countries fell under the low FII category. The remaining countries were in the medium FII category and thus, there was no country with a high FII. Despite that, the poor countries were generally getting better as the number of countries in the low FII category decreased over the years.

The findings suggest that richer countries have higher income and thus higher level of financial inclusion. This is because countries with high income are often associated with having a high account ownership. Various literature also suggest that greater incomes cause people to demand for and utilize more of formal financial services, thus increasing the level of financial inclusion (Asuming, Osei-Agyei, \& Mohammed, 2019; Khanh, 2019; Zins \& Weill, 2016).

\section{FII and Economic Development}

Table 7: Regression Results

\begin{tabular}{cc} 
Variable & OLS Regression \\
\hline LNGDP & $0.076^{* * *}$ \\
& $(0.004)$ \\
Constant & $-0.419^{* * *}$ \\
& $(0.038)$ \\
Adjusted & 0.351 \\
F-Statistic & $250.020^{* * *}$ \\
\hline
\end{tabular}

Note: The dependent variable is the country's financial inclusion index (FII) value, while LNGDP is the natural logarithm of the country's GDP per capita (in current USD). The value in parentheses is the standard error. ${ }^{* * *}$ indicates statistical significance at $1 \%$ level.

The LNGDP had the expected positive coefficient and it was statistically significant at the $1 \%$ level of confidence, meaning that economic development matters in explaining financial inclusion. More developed economies tend to have higher per capita income and thus have a more inclusive financial system. Our analysis of the FII levels in the previous section is in line with this finding as all countries in the high FII category were rich countries, while those in the low FII categories are poor countries. This finding is also consistent with past studies, proving that economic development is one of the most important factors in explaining the level 
of financial inclusion (Beck et al., 2007; Evans \& Adeoye, 2016; Kendall et al., 2010; N. Kumar, 2013; Sarma \& Pais, 2011; Wang \& Guan, 2017). In addition, the $\mathrm{R}^{2}$ shows that the LNGDP was able to explain $35.1 \%$ of the variation in financial inclusion. Furthermore, the inclusion of relevant indicators improved the robustness of the index as it accurately captured important information on financial inclusion which have not done by previous studies such as Sarma (2008) and Amidžić et al. (2014). The findings of this study provide evidence that the proposed FII is valid, reliable and robust enough to be used as a measurement for the level of financial inclusion in a particular country.

\section{CONCLUSION}

This paper provides preliminary evidence on the level of financial inclusion in various developing economies for the most recent years, 2013-2019. In general, developing economies display a low level of financial inclusion with an average FII value of 0.174 . However, the results showed that these countries are at various levels of financial inclusion, ranging from abysmally low FII (less than 0.05) to extremely high (more than 0.8). Countries like Singapore and Lebanon have achieved a high level of financial inclusion as expected for richer economies. Some countries performed moderately well with FII values ranging from 0.308 (Nepal) to 0.441 (Bangladesh). On the other hand, financial inclusion remained low in the rest of the developing world especially in the African region and among poorer countries (i.e., lowincome and lower-middle income). Nevertheless, there are some exceptions to these observations. Lower-middle income countries like Bangladesh and India had a higher level of financial inclusion than several high-income countries such as Brunei and Saudi Arabia. Nepal, a low-income country, also ranked higher than these high-income economies.

In addition, the trends in financial inclusion over the years indicated that there is an improvement in financial inclusion in general. This was evident as the number of countries in the low FII category decreasing resulted from the gradual increase in the number of countries in the medium FII category. Furthermore, the regression analysis of financial inclusion and economic development indicate that countries with high economic development tend to have higher financial inclusion. This finding shows 
that economic development is one of the main factors influencing financial inclusion and further establish the reliability of the newly constructed index.

This study is subject to some limitations. First, due to data constraints, only physical access (i.e., ATM and branches) could be measured. Second, while there are various other factor affecting financial inclusion, this study only took into account the effect of economic development. These offer room for improvements in future research. As the financial sector is now moving beyond traditional banking channels, it is recommended to include other indicators such as mobile and internet banking. It is also recommended to include other relevant factors into the empirical model such as inequality, education, gender, unemployment and poverty to name a few. More countries could also be added in the sample to make the index more robust. These suggestions could be made possible as more data will be available in the future. Despite this limitation, the initial findings could be useful for policymakers and multilateral agencies to develop financial inclusion policies in developing economies which houses almost half of the global unbanked population

\section{ACKNOWLEDGEMENT}

The authors would like to acknowledge the assistance from the Ministry of Higher Education for HICoE research funding, Accounting Research Institute, Universiti Teknologi MARA, Malaysia for all supports and resources.

\section{REFERENCES}

Abu Seman, J. (2016). Financial inclusion: The role of financial system and other determinants. University of Salford. Retrieved from http:// usir.salford.ac.uk/42264/

Allen, F., Carletti, E., Cull, R., Qian, J. Q. J., Senbet, L., \& Valenzuela, P. (2014). The African financial development and financial inclusion gaps. Journal of African Economies, 23(5), 614-642. 
Amidžić, G., Massara, A., \& Mialou, A. (2014). Assessing countries' financial inclusion standing: A new composite index (IMF Working Paper Series No. 14/36).

Arora, R. U. (2010). Measuring financial access (Discussion Papers in Economics No. 2010-07). Gold Coast.

Arora, R. U. (2014). Access to finance: An empirical analysis. The European Journal of Development Research, 26(5), 798-814.

Asuming, P. O., Osei-Agyei, L. G., \& Mohammed, J. I. (2019). Financial inclusion in Sub-Saharan Africa: Recent trends and determinants. Journal of African Business, 20(1), 112-134.

Beck, T., Demirguc-Kunt, A., \& Martinez Peria, M. S. (2007). Reaching out: Access to and use of banking services across countries. Journal of Financial Economics, 85(1), 234-266.

Beck, T., Demirguc-Kunt, A., \& Peria, M. S. M. (2008). Banking services for everyone? Barriers to bank access and use around the world. World Bank Economic Review, 22(3), 397-430.

Bongomin, G. O. C., Munene, J. C., Ntayi, J. M., \& Malinga, C. A. (2015). Financial intermediation and financial inclusion of the poor: Testing the moderating role of institutional pillars in rural Uganda. International Journal of Ethics and Systems, 34(2), 146-165.

Cámara, N., \& Tuesta, D. (2014). Measuring Financial Inclusion: A Multidimensional Index (BBVA Research Working Paper No. 14/26). Madrid.

Cámara, N., \& Tuesta, D. (2017). Measuring financial inclusion: A multidimensional index. In Bank of Morocco-CEMLA-IFC Satellite Seminar at the ISI World Statistics Congress on Financial Inclusion (pp. 1-23). Marrakech: Bank for International Settlements.

Chakravarty, S. R., \& Pal, R. (2013). Financial inclusion in India: An axiomatic approach. Journal of Policy Modelling, 35(5), 813-837. 
Demirguc-Kunt, A., Beck, T., \& Patrick, H. (2007). Acess to Finance and Development: Theory and Measurement. In Finance for all? : Policies and pitfalls in expanding access (pp. 21-54). Washington DC: World Bank.

Demirguc-Kunt, A., Klapper, L., Singer, D., Ansar, S., \& Hess, J. (2018). Global Findex Database 2017: Measuring Financial Inclusion and the Fintech Revolution. Washington DC.

Evans, O., \& Adeoye, B. (2016). Determinants of financial inclusion in Africa: A dynamic panel data approach. University of Mauritius Research Journal, 22, 1-23.

Ghosh, S. (2012). Determinants of banking outreach: An empirical assessment of Indian States. The Journal of Developing Areas, 46(2), 269-295.

Goel, S., \& Sharma, R. (2017). Developing a financial inclusion index for India. Procedia Computer Science, 122, 949-956.

Gupte, R., Venkataramani, B., \& Gupta, D. (2012). Computation of financial inclusion index for India. Procedia - Social and Behavioral Sciences, 37, 133-149.

Gustafson, S., \& Khander, S. (2016). How microfinance has reduced rural poverty in Bangladesh | IFPRI: International Food Policy Research Institute. Retrieved June 17, 2021, from https://www.ifpri.org/blog/ how-microfinance-has-reduced-rural-poverty-bangladesh

Hannig, A., \& Jansen, S. (2010). Financial inclusion and financial stability: Current policy issues (ADBI Working Paper Series No. 259). Tokyo: Asian Development Bank Institute.

International Monetary Fund. (2020). Financial Access Survey - IMF Data. Retrieved September 2, 2021, from https://data.imf.org/

Kainth, G. S. (2013). Developing an index of financial inclusion. Anvesha the Journal of Management, 6(2), 1-11. 
Kempson, E. (2004). Policy level response to financial exclusion in developed economies: Lessons for developing countries. Access to Finance: Building Inclusive Financial Systems. Bristol.

Kendall, J., Ponce, A., \& Mylenko, N. (2010). Measuring financial access around the world (Policy Research Working Paper No. 5253).

Khanh, L. C. (2019). Determinants of financial inclusions: Comparing high, middle, and low-income countries. Economics Bulletin, 39(2), 1449-1457.

Kumar, C., \& Mishra, S. (2011). Banking Outreach and Household level Access: Analyzing Financial Inclusion in India. In 13th Annual Conference on Money and Finance in the Indian Economy (pp. 1-33). Mumbai: Indira Gandhi Institute of Development Research.

Kumar, N. (2013). Financial inclusion and its determinants: Evidence from India. Journal of Financial Economic Policy, 5(1), 4-19.

Mukaka, M. (2012). A guide to appropriate use of Correlation coefficient in medical research. Malawi Medical Journal, 24(3), 69-71.

Mukherjee, S., \& Malik, S. S. (2015). Is Financial Inclusion Cause or Outcome? A State-Wise Assessment in India (Working Paper Series No. 132/2015). Chennai.

Nathan, H. S. K., Mishra, S., \& Reddy, B. S. (2008). An Alternative Approach to Measure HDI (IGIDR WP Series No. WP-2008-001). Mumbai.

OECD. (2008). Handbook of Constructing Composite Indicators: Methodology and user guide. Paris: OECD Publishing. Retrieved from https://www.oecd.org/sdd/42495745.pdf

Okpara, G. C. (2013). Developing an index of financial inclusion: An average ratio approach (MPRA Working Paper Series No. 49505). Uturu. 
Park, C.-Y., \& Mercado, R. J. (2018). Financial inclusion, poverty, and income inequality. The Singapore Economic Review, 63(01), 185-206.

Piñeyro, Z., \& Manuel, C. (2013). Financial inclusion index: Proposal of a multidimensional measure for Mexico. Revista Mexicana de Economía y Finanzas, 8(2), 157-180.

Porteous, D. (2009). Key issues in design and implementation of surveys on financial inclusion. AFI Global Policy Forum, (September). Retrieved from https://www.afi-global.org/

Ratner, B. (2009). The correlation coefficient: Its values range between $+1 /-1$, or do they? Journal of Targeting, Measurement and Analysis for Marketing, 17(2), 139-142.

Salazar, D., Marra, A., Shnayerson, B., \& Menon, A. (2018). The next frontier in financial inclusion: Moving beyond access to usage. Mastercard Center for Inclusive Growth.

Sarma, M. (2008). Index of financial inclusion (Indian Council for Research on International Economic Relations Working Paper Series No. 215). New Delhi.

Sarma, M. (2016). Measuring Financial Inclusion for Asian Economies. In S. Gopalan \& T. Kikuchi (Eds.), Financial Inclusion in Asia (pp. 3-34). London: Palgrave Macmillan UK.

Sarma, M., \& Pais, J. (2011). Financial inclusion and development. Journal of International Development, 23(5), 613-628.

Scottish Executive. (2005). Financial Inclusion Action Plan. Closing the Opportunity Gap. Edinburgh.

Sethy, S. K. (2016). Developing a financial inclusion index and inclusive growth in India. Theoretical and Applied Economics, XXIII(2), 187-206. 
Shrestha, P. K. (2020). Changing dimension of financial inclusion in Nepal: A comparative analysis (NRB Working Paper No. 50).

Swamy, V., \& Tulasimala, B. K. (2011). Financial intermediaries and economic development: Transaction costs of borrowing by the poor. The International Journal of Banking and Finance, 8(3), 54-72.

Tavakol, M., \& Wetzel, A. (2020). Factor analysis: A means for theory and instrument development in support of construct validity. International Journal of Medical Education, 11, 245-247.

UN Capital Development Fund. (2019). Financial inclusion and the SDGs. Retrieved February 15, 2019, from http://www.uncdf.org/financialinclusion-and-the-sdgs.

Wang, X., \& Guan, J. (2017). Financial inclusion: Measurement, spatial effects and influencing factors. Applied Economics, 49(18), 1751-1762.

World Bank Group. (2018). Financial Inclusion on the Rise, But Gaps Remain, Global Findex Database Shows. Retrieved August 28, 2018, from http://www.worldbank.org/en/news/press-release/2018/04/19/ financial-inclusion-on-the-rise-but-gaps-remain-global-findexdatabase-shows.

Yorulmaz, R. (2016). Construction of a financial inclusion index for the member and candidate countries of the European Union. Court of Accounts Magazine, 102(3), 91-106.

Zins, A., \& Weill, L. (2016). The determinants of financial inclusion in Africa. Review of Development Finance (Vol. 6). University of Cairo. 